\title{
THE DEVELOPMENT OF DANISH \\ WORKING ENVIRONMENT REGULATION \\ OF THE HEALTH AND SAFETY \\ ORGANISATION - ORGANISATIONAL \\ UNDERSTANDING AND PROGRAMME \\ THEORY
}

\author{
Rikke Seim, Niels Møller \& Per Langaa Jensen \\ Department of Management Engineering, Technical \\ University of Denmark
}

\begin{abstract}
The Danish law on working environment has been revised in 2010. From mandatory rules on how to organise the activities the new law opens for local decisions on how to organise the activities. As such this law can be seen as a further move towards a reflexive regulation. As part of an evaluation of this new element this paper analyses the program theory being the outcome from the three-partite discussions and negotiations.
\end{abstract}

Key word: Work environment, occupational health and safety, program theory.

\section{Introduction}

This paper focuses on a recent major amendment of the Danish Working Environment regulation which came into force in October 2010. More specifically, we analyse the mechanisms and programme theory that the different elements of the reform subscribe to. The analysis is primarily based on the texts in the law's amendments and additional material from the authorities.

\section{The Danish Work Environment Act}

The present Danish regulation of occupational health and safety (OHS) is rooted in the Working Environment Act passed in 1975 and subsequently modified several times. The law was passed by parliament after a long debate in a tri-partite committee comprising state and labour market organisations, which reached a general consensus.

The general aim of the law has been unchanged. It is stated in the first paragraph:

\section{Part 1: Objectives and scope}

The provisions of this Act shall have effect with a view to creating:

1) a safe and healthy working environment which is at all times in accordance with the technical and social development of society, and

2) the basis upon which enterprises themselves will be able to solve issues relating to health and safety under the guidance of the employers' and workers' organisations, and under the guidance and supervision of the Working Environment Authority. (WEA, 2011, §1)
When the law was passed, the emphasis on 'safe and healthy' indicated a new and broader perspective on issues to be addressed at the workplace. The objective's item 2 emphasises the importance of establishing local initiatives at enterprise level to comply with the law. The law, supplemented with departmental orders, also gave in its earlier forms strict specifications for how to organise such local activities.

The law stated that management had the general obligation to assure a safe and healthy working environment, but this obligation should be fulfilled in cooperation with first-line managers and employees. To frame this cooperation, a mandatory 'safety-organisation' should be established in enterprises with more than 20 employees. This safety organisation within the enterprise should comprise a 'safety group' for each department in the enterprise and a 'safety committee' responsible for all safety groups and for directing and coordinating their activities. The safety groups' members would be the firstline manager of the department and a safety representative elected by the department's employees. The safety committee's members would be representatives from top-management, two representatives elected among the first-line managers in the safety groups, and two representatives elected among the safety representatives. Besides the general obligation to work for a safe and healthy working environment, other issues to be addressed where mentioned in specific departmental order. These included such issues as investigating accidents, risk assessment (workplace assessments), substitution of chemical substances, and assessing plans for developing production with an OHS perspective, as well as handling present problems related 
to occupational health and safety (WEA, 2001; §15a, §49 and EOCSH, 2010).

The law contains a range of assumptions regarding the way to conduct health and safety activities as well as the characteristics of social relations in the company. The ideology behind the law was and still is an assumed harmonious relationship between management, workers and their representatives. Giving the safety representative legal protection against being sacked, however, indicates that there may be situations and enterprises, where this assumption of harmony between the actors does not hold. In addition, the regulation of the health and safety activities in the company can be characterised as reflexive, emphasising goals to be accomplished and procedures to follow (Frick, 2000). In this paper, however, we track the organisational programme theory in relation to the law.

As already described, an organisational unit (the safety organisation comprising the safety groups and the safety committee) was imposed as a mandatory requirement on organisations with more than 20 employees. Analysed from an organisational perspective, the construct established by the law covers all of the elements in Leavitt's (1961) model, pointing out the importance of alignment between structure, tools and procedures, actors and tasks as shown in figure 1 . The law appoints the central actors and makes educational activities to develop the necessary competences mandatory. Guiding material from the labour inspectorate stipulates a set of more specific activities and procedures to follow and tools to apply in combination with the general obligations. But since the organisational frame is mandatory for all enterprises, the law expresses the assumption that 'one size fits all' or 'the one best way' to organise the activities. The basic reference is a medium-sized industrial enterprise with around 150 employees, three hierarchically organised layers and a limited number of departments. It can be noted that the assumption of one best way to organise activities was abandoned by scholars within organisational theory 10 to 15 years before this law was passed (Burns \& Stalker, 1968).

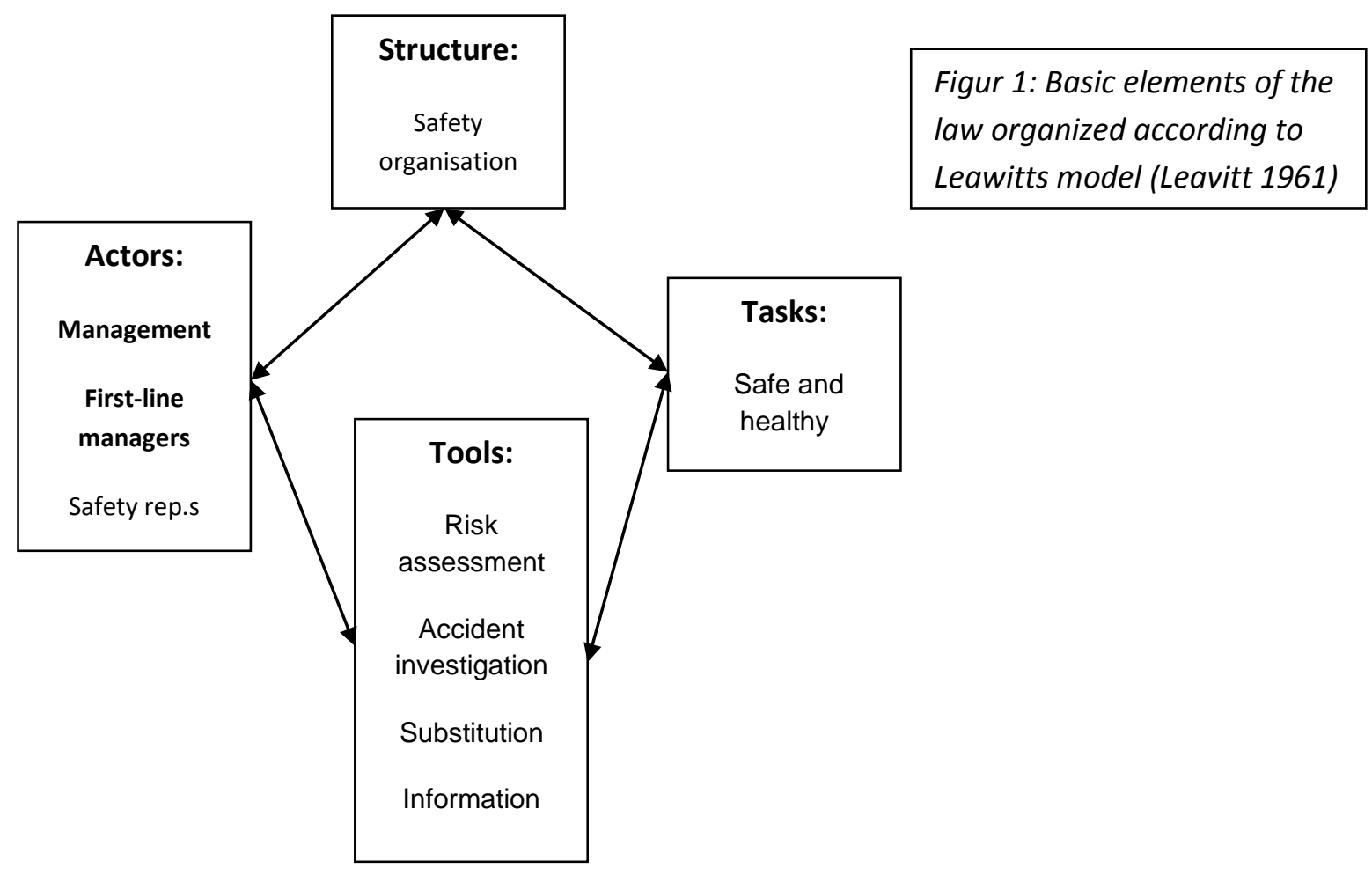

Although the safety organisation was designed according to well-known bureaucratic principles, the stakeholders behind the law also gave different interpretations of what was established through the passage of the law. Employers' organisations conceived it as a staff organisation to give advice on occupational health and safety to the rest of the organisation, while the labour organisations conceived of the safety organisation as a legitimate platform for employees' influence on their working conditions.

Although the law emphasises the importance of coordination with production planning and management, the logic of the law is delimited to the OHS activities.
This also became evident in studies of how the law functioned. The results from many studies can be summarised by the concept of 'the sidecar functioning of the health and safety organisation' (Dawson \& Jensen, 2001), which refers to a situation characterised by the following:

- Management gives verbal support to the activities but does not follow up with expectations for actions expressed in goals or results. As a consequence, OHS issues are omitted from the planning processes where the most effective and least expensive preventive effort could be established. 
- Employees are not eager to be elected to the safety groups; therefore, the representatives are typically rather passive.

- First-line managers consider the job as just 'another job' that has to be taken care of, often without great enthusiasm.

- A consequence of the level of motivation among the actors involved is that the safety organisation exists isolated from other decision-making activities in the enterprise. Their role is to point to OHS issues forgotten in the primary decisions and argue for repairing investments already made. To reduce this role, the safety organisation often ends up handling simple problems with simple solutions that do not involve other departments.

These results indicate that the basic idea (reflexive, proactive and preventive) behind the law was generally not internalised by most enterprises. Issues concerning occupational health and safety were referred to an organisational entity not linked to 'essential' decisionmaking processes in the enterprise, thus eliminating possibilities to establish proactive prevention-oriented activities. Instead, problem-solving reactive activities dominated. The research shows that the unsatisfactory results of the law were ascribed to lack of possibilities for alignment between the safety organisational standard model and the very different organisational design in reallife companies.

The results from these studies led in 2008 to a process aimed at modifying the law in order to assure improved functioning by expanding the law's reflexive elements, giving enterprises the possibility to deviate from the specified organisational structure "...in order to enhance cooperation in the enterprise on health and safety” (WEA, part 2, §7). In the Danish translation, 'enhance' is expressed as 'strengthening' and 'making it more efficient'.

In 2010, an amendment to the existing law was passed. This reform is characterised by the following major new elements:

1) The basic conceptual frame has been changed: the 'safety" concept has been replaced by the concept of 'working environment'.

2) The reform opens for flexibility, also in the organisation of the activities, in order to strengthen the activity and make it more effective.

3) It clarifies the distinction between strategic decisions and operational decisions concerning occupational health and safety by introducing a mandatory yearly debate on occupational health and safety activities.

4) Finally, it opens for the right to develop competences for members of the working environment organisation.

The basic understanding of the three parties involved in this reform (i.e. the two labour market organisations and the state, represented by the Danish labour inspectorate) are discussed in the next section, using the concept of 'programme theory'.

\section{The programme theory behind the Danish Working Environment Act}

Pawson (2006) argues that a given initiative to improve a system's performance must been seen as a combination of the programme theory of the group initiating the change and the context in which the initiative must unfold. The programme theory consists of the more or less explicit assumptions within the decision-making group regarding how the elements proposed might accomplish improved system performance. The encounter between the initiatives and the context represents a test of the validity of the assumptions made in the programme theory.

The programme theory behind the reform of the law can be understood as follows:

\section{Element 1: From 'safety' to 'working environment'.}

The parties involved in the reform found that the concept 'safety' refers to events typically experienced in production industries, whereas the concept 'working environment' opens for a broader coverage of issues related to working conditions that characterise other sectors of society, such as psycho-social burdens related to the organisation and management of activities. In this perspective, this basic change reflects the society's development from a society dominated by industry towards a post-industrial society dominated by service and knowledge work.

Therefore, one element in the programme theory is a change in basic concepts. For most people, the concept 'safety' is especially linked to industrial production, which signals limited relevance for other sectors. The broader concept of 'working environment' is more evidently related to the activities to be conducted. This change in concept is not only related to risks. The organisational structure also changes name to working environment committee, the safety representatives become working environment representatives, and the safety manager changes name to working environment coordinator.

\section{Element 2: Increased flexibility}

The reform deviates from the 'one best way' in that it opens for a more flexible organisation that is adjusted to the 'rest' of the organisation of the enterprise. According to the wording, the argument for deviating from the standard model should be based on the aim to make the activities more efficient and effective.

It is stated, that:

16.-(1) In cooperation with the employees and supervisors, the employer shall determine how many members and how many health and safety groups are required in the health and safety organisation on the basis of the principle of 
proximity.

(2) The number of members and health and safety groups shall be determined in such a manner that the health and safety organisation shall at all times be able to carry out its activities in a satisfactory way in relation to

1. the management structure of the enterprise,

2. the structure of the enterprise in general, including geographical conditions, size and location,

3. the health and safety conditions of the enterprise, including the nature of the work performed, danger, risks and positive health and safety factors,

4. the organisation of the work,

5. special employment terms, and

6. other considerations that affect the health and safety activities of the health and safety organisation. EOCSH, (2010)

It can be noted that the formulation in the principles to be taken into consideration in designing the working environment organisation do not explicitly address issues concerning a fundamental preventive approach by integrating working environment issues into the essential planning and decision-making processes in the enterprise.

The formulation implies that if consensus can be reached locally, the number of people involved can be determined locally. The law also demands equal representation of first-line managers and working environment representatives.

Thus, this element within the programme theory assumes that an organisation tailored to and aligned with the overall organisation will lead to more effective organisation of the preventive health and safety work and increased motivation for the activities.

Moving away from specific demands regarding how to organise the working environment demonstrates a further move towards reflexive regulation. In this situation, the law specifies the general purpose and task but leaves it to the enterprise to decide how they best can be achieved.

\section{Element 3: Operational and strategic working environment activities}

The Danish law on working environment emphasises the importance of having both a strategic and operational perspective on initiatives concerning occupational health and safety. In the original formulation of the law, the strategic aspects were assigned to the safety committee (where representatives from top-management are present), while the operational duties were assigned to the safety groups. This distinction has been accentuated in the new modifications to the law. In the presentation of the amendments to the law, it is explicitly stated by the political parties involved that:
...Working environment shall be part of both the strategic management of the enterprise and the day-to-day operations...

...Working environment issues ought to be discussed in the existing arenas for discussion of strategy, basic values, planning, quality, economy etc.

Top management ought to integrate aspects of relevance for working environment in all processes in the company and do it in cooperation with employees (Rapport from the three-party discussions on the work environment activities in enterprises, 2009), authors' translation).

This element of the programme theory - emphasising the combination of strategic and operational activities - has been accentuated by many actors commenting on the law (labour market organisations, professional advisors within occupational health and safety, and researchers), although it is striking that this issue is not especially addressed in the law. The expectation of the parties involved in the negotiations that led to the reform is that working environment activities will become proactive by being integrated in strategies and the plans derived from them.

The strategic discussion might be backed up by a new element introduced in the amendments to the law: the mandatory annual 'discussion on working environment'. It is stated:

9.-(1) In enterprises with a health and safety organisation, the employer shall conduct health and safety talks with the members of the health and safety organisation every year, and

1. plan the content of the health and safety activities of the enterprise for the forthcoming year,

2. determine how this cooperation shall take place, including forms of cooperation and how often meetings shall be conducted,

3. assess whether the enterprise has achieved the goals set for the previous year, and

4. define goals for cooperation in the forthcoming year.

(2) The employer shall be able to provide written documentation to the Danish Working Environment Authority that the annual talks on health and safety have taken place. (EOCSH, 2010).

This relatively modest tool has played a central role in the discussions of the law reform; however, it must be noted that in the present formulation the strategic activities are focused on formulating a strategy for working environment activities and not on how to integrate working environment issues into the general strategy of the enterprise.

In any case, this element contributes to the programme theory by emphasising a proactive, jointly decided set of goals, decision making regarding a general frame for cooperation to achieve these goals, and finally, a joint 
evaluation of goal achievement, with top management supporting these decisions and evaluations.

It must be noted that the whole formulation of this element of the programme theory is based on a relatively rational understanding of organisational functioning. The strategies are formulated by top management and set a general direction for all decision making in the enterprise. This direction is expected to be followed. Polemically, this basic assumption can be pictured with management as the 'head' of the organisation and the rest of the employees as the organisation's 'body', implementing the signals sent from the head.

\section{Element 4: Development of competences}

The reform reduced the mandatory education for safety representatives and first-line managers from five to three days. In addition to the three-day basic introductory course, an opportunity for supplementary education for the members of the working environment organisation is provided. According to the reform, new members, during their first year in function, should be offered a 2-day supplementary course in addition to the basic introductory course. In addition, each year, all members of the working environment organisation are to be offered 1.5 days supplementary education. It is stated:

38. The objective of supplementary health and safety training is to ensure regular updates in the area that strengthen the skills of health and safety representatives and supervisors in the health and safety organisation. Supplementary health and safety training shall impart knowledge and skills that are relevant with regard to health and safety activities in the enterprise (EOCSH, 2010)

It is thus left to the enterprise to decide which subjects to address in this education. Besides, it should be noted that the supplementary education is not mandatory. It is an offer to the members of the safety organisation.

This component of the reform contributes to the programme theory by presuming that upgrading the qualifications of the members of the working environment organisation will lead to an improvement in the organisation's activities.

\section{Additional initiatives}

Inspection by the public authority (Danish Working Environment Authority) is also an agent who may affect the enterprise's working environment activities. In combination with the reform, the inspection practice was changed. Priority shall be given to a positive dialogue between inspectors and enterprise management. Although traditional inspections are not dismissed, a triviality limit is introduced.

This change in practice reflects the experience of the authorities that enterprises find inspectors' behaviour unnecessarily bureaucratic. It is expected that an approach emphasising dialogue will have a positive effect on motivation to improve the working environment.

\section{Discussion - the element of freedom in the Danish WE regulation}

The basic idea behind the reform can be expressed as follows: By reducing emphasis on compliance and allowing the freedom to decide on and align the organisation of the activities, a more effective set of working environment activities can be expected.

The reform increases the enterprise's freedom. Within the goals and intentions behind the law, and with the intention to increase the effectiveness and efficiency of working environment activities, enterprises have the possibility to reach agreement with the worker representatives on the number of representatives and the organisational structure for carrying out the activities. The argument is that deciding over the organisational structure implies alignment with the enterprise's traditions for management and organisation. It is also expected that it will lead to a reduction in unnecessary working environment activities.

The arguments for to the reform have - with reference to research findings - several references to the existence of positives motives for the enterprise to increase the effectiveness of the working environment activities. For example: "The effort within work environment has high priority because a positive work environment leads to reduced costs". It is also argued that well-functioning and professional management practice, including employee participation, can be transferred to the field of working environment. There are only limited references to the prevention of serious effects on health resulting from ineffective working environment activities.

Several of the parties involved have named the reform 'The Reform of Good Intentions'. This reflects a strategy based on the assumption that more enterprises are willing and able to conduct a more effective and efficient set of working environment activities than before.

Finally, the parallel to the development in organisational theory can be noted. The 'one best way' of organising activities - as promoted by Taylor - has been replaced by a contingency approach, where environment and task complexity play a central role. Correspondingly, detailed rule regulation as promoted by Weber has been replaced with management by objectives, emphasising allocation of resources and development of performance measures. Compared to this development, it is remarkable that the discussion of resources and performance indicators is not addressed by the parties involved.

\section{Conclusion}

With references to central texts that were output from the reform negotiations, we have in this paper deduced the programme theory agreed upon by the parties involved. Through compromises, they reached an agreement on what they believe will initiate activities concerning working environment issues in enterprises.

We have argued that the following four elements constitute the major components in the programme theory of the reform: 
1. A change in the basic concepts to emphasise 'working environment' instead of 'safety' will reveal the relevance of the activities for other sectors than industry and broaden the perspective to other issues than accident prevention.

2. Opening possibilities for local decisions on how to organise the working environment activities as opposed to the former 'one size fits all'approach. This will support the development of more effective and efficient activities within the field. Efficiency involves the amount of resources used within the field, while effectivity concerns better performance with regard to working environment.

3. Setting up a new structural frame - the mandatory annual discussions on work environment -will support development of a strategy for working with working environment, setting the frame for the operational activities within the field.

4. Formalizing the continuous development of qualifications for members of the working environment organisation will increase knowledge and competences within the field.

Additionally, it can be noted that the basic assumption of a harmonious relation between the actors involved in working environment activities has characterised the Danish legislation, with the modification that the representatives are given the same protection as a shop steward. This basic position is maintained in the present reform. This can be seen as a reflection of a general development in the political climate, moving from a radical position that sees working environment as a central field of conflict between employees and employers towards a harmonious position focusing on the possibilities for compromises of interests. It benefits the interests of both parties to assure good working conditions and to establish participatory programmes.

The viability of the programme theory will be demonstrated when it is introduced in specific contexts. We are presently working on a study to analyse what actually happens in enterprises. The study will address the following questions:

- Which enterprises are reorganising their working environment activities?

- What characterises these enterprises?

- How do they operationalise the effectivity and efficiency of their working environment activities?

- Which challenges do they have to address in this process?

- What changes in performance result from this reorganisation?

At the conference the first empirical results and theoretical reflections derived will be presented.

\section{References}

Burns, T. \& Stalker, G.M. (1968). The Mangement of Innovation. Tavistock Publications

Dawson, P. \& Jensen, P.L. (2001): Working Environment and Technological Development: The Danish Experience, editorial in Human Factors and Ergonomics in Manufacturing vol. 11, no. 2, p. 81-87.

EO CSH (2010): Executive Order No. 1181 of 15 October 2010 issued by the Danish Working Environment Authority - unofficial version, The Danish Working Environment Authority; Copenhagen.

http://arbejdstilsynet.dk/en/engelsk/regulations/ executive-orders/1181-samarbejde-sikkerhedsundhed.aspx, 120913.

Frick, K., Jensen, P.L., Quinlan, R. \& Wilthagen, T. (ed.) (2000): Systematic Occupational Health and Safety Management - Perspectives on an International Development. London: Pergamon-

Leavitt, H.J. (1961). Applied organizational change in industry: Structural, technological and humanistic approaches in: J.G. March (ed.), Handbook of organizations Rand McNally, Chicago (1961), pp. 1144-1170.

Pawson, R. (2006) Evidence-based policy: A realist perspective. Sage Publications, London.

WEA (2011): The work environment act. The Danish Working Environment Authority, Copenhagen. http://arbejdstilsynet.dk/en/engelsk/regulations/wo rking-environment-act/arbejdsmiljoeloven1.aspx, 120704. 